\title{
Enhanced viability of corneal epithelial cells for efficient transport/storage using a structurally-modified calcium alginate hydrogel
}

Article

Accepted Version

Wright, B., Cave, R. A., Cook, J. P., Khutoryanskiy, V. V., Mi, S., Chen, B., Leyland, M. and Connon, C. J. (2012) Enhanced viability of corneal epithelial cells for efficient transport/storage using a structurally-modified calcium alginate hydrogel.

Regenerative Medicine, 7 (3). pp. 295-307. ISSN 1746-076X doi: https://doi.org/10.2217/rme.12.7 Available at https://centaur.reading.ac.uk/26137/

It is advisable to refer to the publisher's version if you intend to cite from the work. See Guidance on citing.

To link to this article DOI: http://dx.doi.org/10.2217/rme.12.7

Publisher: Future Medicine

All outputs in CentAUR are protected by Intellectual Property Rights law, including copyright law. Copyright and IPR is retained by the creators or other copyright holders. Terms and conditions for use of this material are defined in the End User Agreement. 


\section{www.reading.ac.uk/centaur}

\section{CentAUR}

Central Archive at the University of Reading

Reading's research outputs online 


\section{Enhanced Viability of Corneal Epithelial Cells for Efficient Transport/Storage Using a Structurally-Modified Calcium Alginate Hydrogel}

Bernice Wright, ${ }^{1}$ Richard A.Cave, ${ }^{1}$ Joseph P. Cook, ${ }^{1}$ Vitaliy V. Khutoryanskiy, ${ }^{1}$ Shengli $\mathrm{Mi}^{1,2}$ Bo Chen, ${ }^{1}$ Martin Leyland ${ }^{3}$ and Che J. Connon ${ }^{1, \dagger}$

${ }^{\dagger}$ Author for correspondence: Che J. Connon; Address: Stem Cells and Nanomaterials Laboratory, School of Pharmacy, Hopkins Building, University of Reading, RG6 6UB, UK. Tel: +44 (0)1183787053 Fax: +44 (0) 8712514665 E-mail: c.j.connon@reading.ac.uk

${ }^{1}$ University of Reading, School of Pharmacy, Reading, Berkshire, RG6 6UB, UK ${ }^{2}$ Shaanxi Institute of Ophthalmology, Xian, People's Republic of China, post code: 710002

${ }^{3}$ Royal Berkshire Hospital, Reading, Berkshire, RG1 5AN, UK 


\section{ABSTRACT}

\section{Aims}

Therapeutic limbal epithelial stem cells could be managed more efficiently if clinically validated batches were transported for 'on-demand' use.

\section{Materials and Methods}

In this study, corneal epithelial cell viability in calcium alginate hydrogels was examined under cell culture, ambient and chilled conditions for up to 7 days.

\section{Results}

Cell viability improved as gel internal pore size increased, and was further enhanced with modification of the gel from a mass to a thin disc. Ambient storage conditions were optimal for supporting cell viability in gel discs. Cell viability in gel discs was significantly enhanced with increases in pore size mediated by hydroxyethyl cellulose.

\section{Conclusions}

Our novel methodology controlling alginate gel shape and pore size together, provides a more practical and economical alternative to established cryopreservation methods.

\section{KEYWORDS}

Corneal epithelial cell storage, calcium alginate structure, corneal epithelial cell viability, hydroxyethyl cellulose, calcium alginate gel shape, calcium alginate gel pore size 


\section{INTRODUCTION}

Transplantation of corneal epithelial cells is the principal therapy for a leading cause of corneal blindness, limbal stem cell deficiency (LSCD) [1-2], which develops due to depletion of epithelial stem cells at the limbal region of the cornea. Currently, limbal stem cell transplantation is undertaken in a few specialist hospitals across the developed world. These cells are mainly expanded ex vivo on amniotic membrane, in discrete laboratory facilities associated with hospitals where the transplant is performed. As techniques for limbal stem cell transplantation (LSCT) develop, hospital laboratories involved in production of cells for this therapy may be replaced by larger distribution centres. Inherent benefits of these centres include opportunities to develop a broad base of expertise for cell preservation and shipment, to replace and/or compliment well-established, but less efficient and economical, cryopreservation methods.

In the present study, we hypothesised that biocompatible hydrogels may be applied to the short-term transport/storage of corneal epithelial cells demonstrated to reconstruct functional corneal epithelium in humans presenting LSCD [1-2]. A clear advantage of this method of cell storage in comparison to established cryopreservation methods is that it ensures the quick and easy retrieval of cells at their time of use.

Hydrogels have been applied extensively as cell carriers or 3D cell culture systems [3-21]. Fibrin hydrogels have been used for the delivery of limbal epithelial cells [3], and another biomaterial, electrospun poly(lactide-co-glycolide), has been reported as a biodegradable cell carrier system for these cells [4]. Collagen gels have also been demonstrated as suitable substrates for the expansion and delivery of 
limbal epithelial cells [5-6]. Alginate hydrogels, one of the most well-characterised cell immobilisation substrates [7-13], have been used to encapsulate a wide variety of cell types including retinal ${ }^{7}$ and seminiferous tubule [8] epithelial cells, probiotic bacteria[9], pancreatic islet cells[10], parathyroid cells [11], neuroblastoma cells [12] and fibroblasts/keratocytes [13].

The immuno-isolatry and semi-permeable structure of alginate gels has made this biomaterial an attractive substrate for the transplantation of cells as treatment for diseases including hormone (diabetes [10]) and protein (hypoparathyroidism [11]) deficiency conditions. The structures of alginate gels have also been reported to influence encapsulated cells and tissues [12, 14-16]. Previous reports have demonstrated that an increase in alginate gel porosity enhanced the secretion of proteins and solutes from encapsulated cells [14-16], and changing alginate concentration has been demonstrated to influence the movement of solutes through this gel [14]. The mannuronic and guluronic acid content of alginate gels also determines permeability [17-18].

The present study aims to demonstrate how the structure of a calcium alginate gel may be modified, to allow corneal epithelial cells immobilised within this scaffold to be preserved in a viable state for short periods with limited or no proliferation. We demonstrate that cells are most viable in low alginate concentration gel masses containing relatively larger internal pore spaces than high alginate concentration gel masses. Altering alginate gels from an amorphous mass to a thin disc greatly improved cell viability. Hydroxyethyl cellulose (HEC) was demonstrated to increase pore size in alginate gels in the presence of live cells (ie. to function as a live cell porogen). HEC significantly augmented the viability of encapsulated cells by increasing the size of internal pores. 
This study describes an alginate-based preservation method which may be applied to the transport of corneal epithelial cells used in the treatment of LSCD. 


\section{MATERIALS}

Dulbecco's minimal essential medium (DMEM) and Ham's F12 medium (DMEM/F12,1:1), antibiotics (penicillin/streptomycin), fetal bovine serum (FBS), amphotericin $\mathrm{B}$, dimethylsulphoxide (DMSO), $\mathrm{HCl}$, Whatman chromatography paper, O.C.T (TissueTek) and Trypan Blue were purchased from Thermo Scientific HyClone (Fisher Scientific: Leicestershire, UK). Human epidermal growth factor (hEGF), insulin, sodium alginate (viscosity: $15-20 \mathrm{cP}, 1 \%$ in $\mathrm{H}_{2} \mathrm{O}$ (lit.)), hydroxy ethyl cellulose (HEC: $M_{\vee} 90$ kDa, D.S. 1.5, M.S. 2.5), calcium chloride, 3-(4,5-dimethylthiazol-2-yl)2,5-diphenyltetrazolium bromide (MTT reagent), sodium citrate and sodium chloride were from (Sigma-Aldrich, Poole, UK). The HCE cell-line was from RIKEN BioResource Center (Tsukuba, Ibaraki, Japan). Vectorshield containing 4',6diamidino-2-phenylindole (DAPI) was from Vector Laboratories Ltd. (Peterborough, UK) and osmium tetroxide was from Agar Scientific Ltd (Essex, UK).

\section{METHODS}

\section{Culture of a human corneal epithelial (HCE) cell-line}

A human corneal epithelial (HCE) cell-line [22] was cultured in DMEM/F12,1:1 supplemented with $5 \%$ FBS, $0.5 \%$ DMSO, $10 \mathrm{ng} / \mathrm{ml} \mathrm{hEGF,} 5 \mathrm{mg} / \mathrm{ml}$ insulin, $100 \mathrm{IU} / \mathrm{ml}$ penicillin and $100 \mathrm{mg} / \mathrm{ml}$ streptomycin, at $37^{\circ} \mathrm{C}$ under $5 \% \mathrm{CO}_{2}$ and $95 \%$ humidity. Cells were replenished with fresh medium every 3 days and grown to $70-80 \%$ confluency. 


\section{Isolation of epithelial cells from the cornea}

The established bovine cornea model $[5-6,23]$ was used for the isolation of limbal epithelial cells. Normal bovine eyes were obtained from a local abattoir (Chity whole sale abattoir, Guildford, UK) within $2 \mathrm{~h}$ of death, transported to the laboratory at $4^{\circ} \mathrm{C}$ and used immediately. Corneoscleral buttons were dissected using standard eye bank techniques, as previously described [5-6, 23].

\section{Encapsulation of epithelial cells in calcium alginate gel masses and discs}

HCE and limbal epithelial cells were suspended in $0.3 \%(\mathrm{w} / \mathrm{v}), 0.6 \%(\mathrm{w} / \mathrm{v}), 1.2 \%$ $(\mathrm{w} / \mathrm{v}), 2.4 \%(\mathrm{w} / \mathrm{v})$ and $3.6 \%(\mathrm{w} / \mathrm{v})$ sodium alginate solution with or without $1.2 \%(\mathrm{w} / \mathrm{v})$, 2.4\% (w/v) and 3.6\% (w/v) HEC, before gelling into masses and discs using $102 \mathrm{mM}$ $\mathrm{CaCl}_{2}$. Gel masses and discs were formed by pipetting $2 \mathrm{~mL}$ sodium alginate/cell solutions into approximately $10 \mathrm{~mL} 102 \mathrm{mM} \mathrm{CaCl}_{2}$ and using chromatography paper molds (Whatman) immersed in $102 \mathrm{mM} \mathrm{CaCl}_{2}$ respectively. Briefly, to form gel discs, a paper ring with a $2 \mathrm{~cm}$ diameter opening was placed over a $3 \mathrm{~cm}$ diameter paper disc. These were saturated with $102 \mathrm{mM} \mathrm{CaCl}_{2}$ before alginate or alginate/HEC solution $(420 \mu \mathrm{L})$ was pipetted into the ring. A second $3 \mathrm{~cm}$ diameter paper disc saturated with $102 \mathrm{mM} \mathrm{CaCl}_{2}$ was placed over the alginate/paper assembly. Alginate or alginate/HEC solutions were exposed to $102 \mathrm{mM} \mathrm{CaCl}_{2}$ for $10 \mathrm{~min}$ to allow complete gelation.

Calcium alginate or alginate/HEC gel masses and discs were suspended in supplemented DMEM/F12 medium under cell culture $\left(37^{\circ} \mathrm{C}, 5 \% \mathrm{CO}_{2}, 95 \%\right.$ humidity), ambient $\left(18-22^{\circ} \mathrm{C}\right.$, atmospheric $\mathrm{CO}_{2}$ and humidity levels) and chilled $\left(4^{\circ} \mathrm{C}\right.$, atmospheric $\mathrm{CO}_{2}$ and humidity levels) conditions, for 1, 3, 5, 7 and/or 12 days. Initial experiments performed under ambient and chilled conditions using gels seeded with 
$5 \times 10^{5}$ cells $/ 2 \mathrm{~mL}$ gel, demonstrated a rapid decline in cell viability, that was prevented by reducing cell numbers to $3 \times 10^{5}$ cells $/ 2 \mathrm{~mL}$ gel (under cell culture storage, gels were seeded with $5 \times 10^{5}$ cells $/ 2 \mathrm{~mL}$ gel). Periods of encapsulation were restricted to 7 days under ambient and chilled conditions, as cells did not remain alive for longer periods of time. Gel/cell matrices were replenished with fresh medium every 2 days. Loss of cells from calcium alginate gel masses due to the extraction process was minimal, and non-gelled alginate or alginate/HEC did not significantly affect cell viability.

\section{Cell viability analysis}

Cells were extracted from calcium alginate gel masses and discs using alginate dissolving buffer $(0.15 \mathrm{M} \mathrm{NaCl}, 0.055 \mathrm{M}$ sodium citrate). Cells from individual conditions were cultured in supplemented DMEM/F12 for approximately 3 days for HCE and 2 weeks for limbal epithelial cells to monitor the ability of these cells to attach and form colonies post-extraction. Images of cell colonies were obtained at 100X magnification. The Trypan blue exclusion assay was performed by mixing a 10 $\mu \mathrm{L}$ cell suspension with $10 \mu \mathrm{L}$ Trypan blue dye solution $(\mathrm{v} / \mathrm{v})$, before counting live (unstained) and dead (stained-blue) cells using a haemocytometer. The MTT assay was performed to assess cell metabolic activity, following the manufacturer's protocols. Briefly, $12 \mathrm{mM}$ 3-(4,5-dimethylthiazol-2-yl)-2,5-diphenyltetrazolium bromide was added to a $100 \mu \mathrm{L}$ suspension of cells and this was incubated for $2 \mathrm{~h}$ at $37^{\circ} \mathrm{C}$. Cells were then lysed using dimethylsulphoxide (DMSO), incubated for a further 10 min at $37^{\circ} \mathrm{C}$, mixed and the absorbance of the reaction product (formazan) was measured at $540 \mathrm{~nm}$. 


\section{Scanning electron microscopy (SEM) analysis of calcium alginate structure}

The internal surfaces of calcium alginate and calcium alginate/HEC gels were examined by SEM. Gels were fixed in $1.25 \%(\mathrm{v} / \mathrm{v})$ glutaraldehyde and post-fixed for 2 hours in $1 \%$ aqueous osmium tetroxide, washed in distilled water and passed through a graded ethanol series (50\%, 70\%, $90 \%$ and $100 \%)$ before dehydration through critical point drying. Dehydrated gels were fractured to expose internal surfaces, mounted on aluminium stubs and sputter coated with gold before examination using SEM (FEI Quanta FEG 600, UK).

\section{Determination of alginate $M / G$ ratios}

Alginate solution was prepared in deionised water at a concentration of $2.5 \%(\mathrm{w} / \mathrm{v})$. Alginate solutions $\left(5 \mathrm{~cm}^{3}\right.$ aliquots) were placed in $10 \mathrm{~cm}^{3}$ glass microwave tubes (CEM) and subjected to microwave irradiation using a power input of $200 \mathrm{~W}$, a nominal temperature of $120^{\circ} \mathrm{C}$ and a hold time of 5 minutes. This method was adapted from the microwave-assisted rapid hydrolysis method of Chhatbar et al. (2009) [24], by using a research microwave reactor (CEM Discover LabMate) instead of a domestic microwave oven. The safety cut-off pressure of 200 psi was never reached. Following hydrolysis, the $M / G$ ratio was determined with reference to the method of Chandia et al. (2001) [25]. Briefly, the hydrolysed solution was adjusted to pH 2.85 (monitored with a Mettler Toledo SevenEasy pH meter S20) using $0.1 \mathrm{M} \mathrm{HCl}$ (Fisher) solution and the resulting precipitate, poly(guluronic acid) was collected by centrifugation (Denley BS400) and weighed. The supernatant was adjusted to $\mathrm{pH}$ 1.0 using $0.1 \mathrm{M} \mathrm{HCl}$ solution and the second precipitate, poly(mannuronic acid) was collected by centrifugation and weighed. The value obtained for the M/G ratio was 3.3 
$\pm 0.3(77 \% \mathrm{M} / 23 \% \mathrm{G})$, consistent with the manufacturer's assertion that this alginate has a high $\mathrm{M}$ content.

\section{Analysis of the compressive mechanical moduli of calcium alginate/ HEC hydrogels}

Gel spheres were formed by dispensing $2 \mathrm{~mL}$ alginate or alginate/HEC solutions dropwise into $30 \mathrm{~mL} \mathrm{CaCl} 2(100 \mathrm{mM})$. Gelled spheres were mechanically tested at 1 , $5,10,15,20,25,30,45$ and 60 min to determine the time periods needed for complete gelation. Alginate and alginate/HEC solutions gelled into stable gels after 10-20 min exposure to $102 \mathrm{mM} \mathrm{CaCl}_{2}$. Mechanical testing of gels was achieved by compressing these structures using a TA.XT.plus Texture Analyser (Stable Micro Systems, Surrey, UK) with a $5 \mathrm{~kg}$ load cell and a P/1KS flat ended stainless steel probe (Stable Micro Systems, Surrey, UK) with a $1 \mathrm{~cm}^{2}$ surface area. Measurement of the force was taken, with a trigger force of $0.0005 \mathrm{~N}$, and the yield point of gel spheres (point at which the gels split) was recorded. Force was recorded as the mechanical limit of the gels, described as comparative yield force and 10 measurements of each gel sample were performed.

\section{Analysis of cell distribution in HEC-modified calcium alginate gel discs}

HCE cells were encapsulated in calcium alginate (1.2\% alginate) or HEC-modified calcium alginate (1.2\% alginate/1.2\% HEC, $1.2 \%$ alginate $/ 2.4 \% \mathrm{HEC}$ ) gel discs. Gels were embedded in OCT (TissueTek), frozen and cryosectioned. Transverse sections of gels were mounted on glass slides with Vectorshield containing DAPI fluorescent stain to visualise cell nuclei. Sections were observed by fluorescence microscopy (Carl Zeiss Meditec, Germany). 


\section{Statistical Analysis}

Unpaired Student's t-tests were performed using Microsoft Excel. Results are presented as the mean of 3 individual experiments with standard error of mean and $P$-value $\leq 0.05$ considered significant. 


\section{RESULTS}

\section{Calcium alginate supports corneal epithelial cell viability in a differential manner under various storage conditions}

To examine the suitability of a calcium alginate hydrogel for preservation of corneal epithelial cells, the effects of alginate concentration, storage condition and period of encapsulation on cell viability were investigated.

The viability of human corneal epithelial cells (HCE: SV40-immortalised cellline) within calcium alginate was influenced by polymer concentration, period of encapsulation and storage condition (Figure 1). Cell viability was supported most effectively within $0.6 \%(\mathrm{w} / \mathrm{v})$ alginate gel masses under all storage conditions. Under cell culture storage after a 5 day encapsulation period, a significantly greater proportion $(P \leq 0.05)$ of initially encapsulated cells $\left(5 \times 10^{5}\right)$ were viable in a $0.6 \%$ $(\mathrm{w} / \mathrm{v})$ gel mass $(62 \pm 11 \%)$ than in a $1.2 \%(\mathrm{w} / \mathrm{v})$ gel mass $(25 \pm 5 \%)($ Figures $1 \mathrm{~A}$ and 1D). Under chilled and ambient storage, however, cell viability was supported less effectively. After a 3 day encapsulation period, $57 \pm 14 \%$ of initially encapsulated cells $\left(3 \times 10^{5}\right)$ remained alive under chilled storage and only $33 \pm 4 \%$ of cells recovered from ambient storage were viable.

Post-extraction culture of cells demonstrated that cells from $0.3 \%(w / v)$ (Figures 1G.i, H.i and I.i) and 0.6\% (w/v) (Figures 1G.ii, H.ii and I.ii) alginate gel masses assembled into colonies, but cells from 1.2\% (w/v) gel masses (Figures 1G.iii, H.iii and I.iii) did not attach to culture dishes. Cells recovered from $0.3 \%(\mathrm{w} / \mathrm{v})$ gel masses (Figure 1G.i) assembled into smaller colonies than those from $0.6 \%(\mathrm{w} / \mathrm{v})$ gel masses (Figure 1G.ii) maintained under cell culture storage. This pattern of growth was particularly apparent for cells from ambient (Figure 1H.i-ii) and chilled 
(Figure 1l.i-ii) storage. Furthermore, cells from cell culture storage assembled into larger colonies (Figure 1G.i-ii) than those from ambient (Figure 1H.i-ii) or chilled (Figure 1I.i-ii) storage. Therefore, these data demonstrate that HCE cells can be stored most effectively under cell culture conditions in a $0.6 \%(\mathrm{w} / \mathrm{v})$ alginate gel mass.

By contrast, the viability of physiologically robust primary limbal epithelial cells was supported most effectively under chilled storage in $0.6 \%(\mathrm{w} / \mathrm{v})$ alginate gel masses (Figures $2 \mathrm{~A}$ and $2 \mathrm{~B}$ ). The viability of these cells ( $46 \pm 5 \%$ cells alive) was however, lower than that of HCE cells $(57 \pm 14 \%$ cells alive) maintained under chilled storage in $0.6 \%(\mathrm{w} / \mathrm{v})$ gel masses (see Figures $1 \mathrm{C}$ and $1 \mathrm{~F})$. Despite this reduction in viability, primary epithelial cells proliferated $(174 \pm 45 \%$ of initially encapsulated cells were recovered) after a 3 day encapsulation period within gels under chilled storage. A greater proportion (50\%) of live primary epithelial cells was extracted from alginate gels under chilled storage than from gels maintained under cell culture storage. Cells from cell culture storage, however, assembled into large sheets (Figure 2C.i) whereas those from chilled storage only assembled into small colonies (Figure 2C.ii), after extraction from gels. Under ambient storage, limbal epithelial cell viability was very poor; cells did not remain alive for longer than 3 days (Figures $2 \mathrm{~A}$ and $2 \mathrm{~B}$ ).

Taken together, these data demonstrate that $0.6 \%(\mathrm{w} / \mathrm{v})$ alginate gel masses store corneal epithelial cells most effectively in either a chilled or cell culture environment. These conditions require further optimisation, however, to limit cell proliferation and enhance cell viability. 


\section{The structure of calcium alginate gels may influence the viability of encapsulated cells}

Variations in cell viability between gels formed from different alginate concentrations (see Figure 1) suggested that the structure of gels may affect their ability to support viable cells. Therefore, the internal structures of $0.3 \%(\mathrm{w} / \mathrm{v}), 0.6 \%(\mathrm{w} / \mathrm{v})$ and $1.2 \%$ (w/v) alginate gel masses were examined by SEM.

Gel masses comprised irregular internal pore spaces which increased in size with decreasing alginate concentration (Figure 3). Pore diameters ranged from 0.2$3.0 \mu \mathrm{m}$ within a $0.3 \%(\mathrm{w} / \mathrm{v})$ gel (Figure $3 \mathrm{~A}), 0.1-1.0 \mu \mathrm{m}$ within a $0.6 \%(\mathrm{w} / \mathrm{v})$ gel (Figure 3B) and $0.1-0.4 \mu \mathrm{m}$ within a $1.2 \%(\mathrm{w} / \mathrm{v})$ gel (Figure $3 \mathrm{C})$. Cells were more robustly viable in $0.3 \%(\mathrm{w} / \mathrm{v})$ and $0.6 \%(\mathrm{w} / \mathrm{v})$ alginate gels with large pores than $1.2 \%$ gels with relatively smaller pores (see Figure 1). Therefore the internal structure of alginate gels may influence the viability of encapsulated cells.

The viability of primary epithelial cells is enhanced in thin discs of calcium alginate

Modifications to the shape of alginate gels have been previously shown to enhance the viability of immobilised neuroblastoma cells [12]. We therefore, altered the macrostructure of gels from an amorphous mass (approximately $6 \mathrm{~mm}$ depth and $12.5 \mathrm{~mm}$ width) to a thin disc (approximately $1.5 \mathrm{~mm}$ depth and $19 \mathrm{~mm}$ width) (Figure 4). We hypothesised that the reduced depth of a $1.2 \%(\mathrm{w} / \mathrm{v})$ alginate gel disc would compensate for low cell viability observed in a $1.2 \%(\mathrm{w} / \mathrm{v})$ gel mass, by presenting a shorter distance for mass transfer of nutrients to and waste from immobilised cells, as previously reported [14]. 
Cell viability was enhanced in gel discs (Figure 5) compared to gel masses (compare Figure 2 and Figure 5), and cells did not proliferate within gels. In gel discs, the highest proportions of viable cells were recovered from ambient storage (Figure $5 \mathrm{~A}$ and $5 \mathrm{~B})$, previously demonstrated as unable to support viable cells in $0.6 \%(\mathrm{w} / \mathrm{v})$ gel masses for longer than 3 days (see Figure 2). After a 7 day encapsulation period, $52 \pm 5 \%$ of initially encapsulated cells $\left(3 \times 10^{5}\right)$ remained alive in gel discs under ambient storage (Figure 5A). After 1, 3 and 5 day encapsulation periods, cell viability between gel masses and discs were similar under chilled storage (compare Figure 2 and Figure 5), but after a 7 day encapsulation period a significantly greater $(P \leq 0.05)$ proportion of initially encapsulated cells remained alive in gel discs $(29 \pm 7 \%)$ (Figures $5 \mathrm{~A}$ and $5 \mathrm{~B})$ than in gel masses $(7 \pm 3 \%)$ (Figure $2 \mathrm{~A})$.

As observed within gel masses (see Figure 2), the lowest levels of viable cells were extracted from gels maintained under cell culture storage (Figure $5 \mathrm{~A}$ and $5 \mathrm{~B}$ ). In gel discs, live cells extracted from cell culture storage were, however, able to assemble into cell sheets (Figure 5D.i). This pattern of post-extraction growth was similar to that of live cells from ambient storage (Figure 5D.ii). Although cell viability was robust in gel discs under chilled storage, during post-extraction culture, only single cells from chilled storage adhered to culture dishes (Figure 5D.iii). The mitochondrial activities of cells from chilled and ambient storage were similar (Figure 5C). Therefore, the inability of chilled storage live cells to assemble into colonies or sheets was not due to reduced levels of metabolically active cells.

Collectively, these data demonstrate that modification of the macro-structure of a calcium alginate gel from an amorphous mass to a thin disc enhances corneal epithelial cell viability, limits cell proliferation and overcomes the reduction in cell viability observed with increases in alginate concentration. 


\section{Modification of internal pore sizes of alginate gel discs with HEC significantly enhances corneal epithelial cell viability}

We demonstrated that increases in the size of internal pores in alginate gels correlate with increases in cell viability (compare Figure 1 and Figure 3). Therefore to further enhance cell viability, methods were employed to increase pore sizes in alginate gel discs. HEC was demonstrated to enlarge the size of internal pores within these gels (Figure 6), in the presence of live cells.

Cell viability was markedly increased in alginate gel discs formed in the presence of HEC compared to gel discs without this polysaccharide (Figure 7 and supplementary Figure 1). A $1.2 \%$ (w/v) gel disc supported $60 \pm 11 \%$ encapsulated cells in a viable state whilst modification of these gels with $1.2 \%(\mathrm{w} / \mathrm{v})$ or $2.4 \%(\mathrm{w} / \mathrm{v}) \mathrm{HEC}$ maintained the viability of $100 \%(P \leq 0.01)$ encapsulated cells (Figure 7$)$. Improved cell viability correlated with a decrease in gel stiffness (compressive modulus) (Figure 7) as well as increased pore size (Figure 6). Cells in $1.2 \%(w / v)$ alginate gel discs modified with HEC were more dispersed than those in $1.2 \%(\mathrm{w} / \mathrm{v})$ gel discs without this non-ionic polysaccharide (Figure 8), suggesting that cell distribution may also be affected by gel structure. Gels comprising $2.4 \%(\mathrm{w} / \mathrm{v})$ or $3.6 \%(\mathrm{w} / \mathrm{v})$ alginate supported low levels (20-40\%) of live cells (Figure 7) compared to $1.2 \%(\mathrm{w} / \mathrm{v})$ alginate gels. Cell viability in $2.4 \%(\mathrm{w} / \mathrm{v})$ and $3.6 \%(\mathrm{w} / \mathrm{v})$ alginate gels modified with HEC was not improved, despite increases in pore sizes (Figure 6). This suggests that the increased stiffness of these gels may overcome increases in viability due to enlarged pore size.

These data indicate that the viability of cells encapsulated within calcium alginate gels is influenced by both pore size and mechanical properties. The extent to 
which these structural features affect cell viability may be manipulated by modifying proportions of alginate and porogen (HEC) in gels. 


\section{DISCUSSION}

The transport of live cell cultures presents a significant distribution problem for laboratory supply companies, and emergent therapeutics companies specialising in regenerative medicine. Current distribution solutions, mainly involve cryopreservation and/or cold chain transport which are impractical, economically costly and technically challenging as they either require specialised logistics or can only be performed in limited time delivery windows [26]. Alternatives to these conventional methods for cell distribution may improve the clinical management of therapeutic cells as well as contribute favourably toward the early promise of cell-based regenerative medicine. A hydrogel which is structurally stable at a range of temperatures, biocompatible for cell encapsulation and easily modified to quickly release encapsulated cells (calcium alginate), would be a suitable alternative which may be developed for significant, wide-ranging use in future cell-based therapies.

The present study therefore investigates calcium alginate as a storage module for corneal epithelial cells. The structural dependence of the biocompatibility of this hydrogel is examined. Modifications to the macro-structure, internal microarchitecture and mechanical properties of alginate hydrogels have been previously reported to influence the behaviour of immobilised cells [12, 14-16]. We hypothesised that altering gel shape, pore size and mechanical properties together, may enhance the biocompatibility of alginate hydrogels for use as substrates for corneal epithelial cell storage.

Effective transport of solutes in and out of cell immobilisation scaffolds (ie. alginate hydrogels) is an essential property to ensure their biocompatibility [27-28]. In the present study, modifications to alginate gel shape and internal pore size possibly 
increased the viability of immobilised cells, by causing more efficient mass transfer of nutrients and oxygen to, and metabolic waste from cells by viscous flow [29] through enlarged pores. An increase in alginate gel porosity was reported to enhance ammonia elimination rates of hepatocarcinoma cells [15] and albumin secretion by hepatocytes [16]. Therefore, HEC-mediated increases in alginate-encapsulated cell viability, observed in the present study may be due to the displacement of alginate polymer by HEC, leading to the enlargement of forming pores.

The permeability of alginate gels has also been shown to be dependent on alterations in gel shape [12] and gel stability [14]. Increasing alginate concentration from $1.5 \%$ to $3 \%$ was previously shown to hinder the movement of various solutes through this gel, as $3 \%$ alginate gel internal pore diameters were shorter $(147 \AA)$ than $1.5 \%$ alginate gel internal pore diameters (170 ̊) [14]. Alginate gel permeability is also determined by their mannuronic $(M)$ and guluronic $(G)$ acid content [17-18]; gels with a high $\mathrm{M} / \mathrm{G}$ ratio present a small intrinsic pore size [31]. In the present study, the alginate used comprised a high M percentage $(77 \%)$ and a low G percentage (23\%). The $M / G$ ratio may be manipulated to increase the permeability of gels as necessary to improve the viability of encapsulated cells. High $\mathrm{M}$ alginates are, however, more biocompatible and clinically useful than high $G$ alginates $[18,30]$. Therefore, the method described in this study which incorporates HEC into a high $\mathrm{M}$ alginate gel to modify the porosity of this biomaterial is advantageous, as the gel retains high elasticity and low viscosity conferred by the high $\mathrm{M}$ content.

Cell storage in alginate gels has not been previously investigated alongside the structure of this biomaterial. Reports investigating cell storage in alginate gels have, however, examined the viability of a number of different cell types in alginate gels under both ambient and chilled storage. In the present study, ambient storage 
was the most favourable condition for limbal epithelial cells in alginate gels. Similarly, limbal epithelial cells maintained on amniotic membrane in organ culture medium, have been demonstrated to retain high levels of viability under ambient storage [31]. Spermatozoa stored under ambient conditions in alginate gels, were reported as more functionally robust compared to those not stored in alginate gels [32]. Neuroblastoma cells stored in alginate gels at $4^{\circ} \mathrm{C}$ were reported to retain normal morphological differentiation and adhesion abilities [33], and oocytes stored at $4^{\circ} \mathrm{C}$ were also demonstrated to be functional when restored to physiological environments [34]. By contrast, chondrocytes stored at $4^{\circ} \mathrm{C}$ in alginate gels were only modestly viable [35].

In the present study, the recovery of live corneal epithelial cells from chilled $\left(4^{\circ} \mathrm{C}\right)$ storage was also compromised. These cells did not assemble into colonies when extracted from alginate gels. This may be because cells were undergoing anoikis, programmed cell death that prevents cell attachment [36]. It may be possible to achieve complete recovery of live cells stored under chilled conditions by incorporating $\mathrm{CO}_{2}$ into alginate gels, as the viability of cells stored in alginate gels under chilled conditions has been reported to improve through normalisation of increased pH with $\mathrm{CO}_{2}[35]$.

This study provides the first line of evidence demonstrating how both the macro- and micro-structure of a calcium alginate hydrogel can be modified to support the short-term preservation of corneal epithelial cells. 


\section{FUTURE PERSPECTIVES}

We have evolved alginate encapsulation technology by describing structural modification of this biomaterial for potential use as a transport/storage device applicable to corneal cell-based therapies. We have also demonstrated the novel use of HEC, which enhances the viability of alginate-encapsulated cells by increasing the size of pores within gels in the presence of live cells (a live cell porogen). Future therapy for LSCD, may be improved by using structurally-modified alginate gels as storage capsules for limbal epithelial cells. These cells expanded ex vivo, in batches, could be preserved in alginate gels, and transported to clinical settings under ambient storage conditions. Our methodology for alginate-based cell storage may potentially lead to the exclusive use of allogeneic sources of limbal epithelial stem cells to treat LSCD.

\section{ACKNOWLEDGEMENTS}

The work was funded by the Medical Research Council (MRC) (Grant Ref: G/0900877). Technical assistance: Dr. Chris Stain (University of Reading, Centre for Advanced Microscopy). 


\section{Executive Summary}

\section{Need for effective methodologies for therapeutic cell transport}

- Currently, cells are mainly distributed using cryopreservation and/or cold chain transport which are impractical, economically costly and technically challenging.

- Future cell distribution centres can be designed to develop cell preservation and shipment methodology, that can replace less efficient and economical cryopreservation methods.

\section{Response to need for cell transport methods}

- An alginate-based preservation method which can be applied to the transport of corneal epithelial cells was investigated.

- Alginate hydrogels with modifications to the macro-structure, internal microarchitecture and mechanical properties were examined as cell transport vehicles.

- Corneal epithelial cell viability in structurally-modified calcium alginate hydrogels was examined under cell culture, ambient and chilled conditions.

\section{Suitability of alginate hydrogels as cell transport vehicles}

- Alginate hydrogels are structurally stable at a range of temperatures and are easily modified.

- These gels are biocompatible for cell encapsulation and encapsulated cells can be quickly released. 
- Alginate hydrogels are biocompatible, as the porous structure of these scaffolds allow effective transport of solutes to and from immobilised cells.

\section{FIGURE LEGEND}

Figure 1: The viability of HCE cells stored in calcium alginate gel masses is dependent on polymer concentration, period of encapsulation and storage condition. Data points represent the mean ( $n=3 \pm$ S.E.M.) percentage (cell culture: $A$; ambient: B; chilled: C) $(100 \%$ = initially encapsulated live cells) or number (cell culture: D; ambient: E; chilled: F) of live cells extracted. ${ }^{*} P \leq 0.05$ indicate differences between alginate concentrations. Images ( $n=3 ; 100 X$ magnification) show colonies of cells from cell culture (G.i: $0.3 \%(w / v)$ alginate, G.ii: $0.6 \%(w / v)$ alginate, G.iii: $1.2 \%(w / v)$ alginate), ambient (H.i: $0.3 \%$ alginate, H.ii: 0.6\% alginate, H.iii: $1.2 \%$ alginate) and chilled (I.i: $0.3 \%$ alginate, I.ii: $0.6 \%$ alginate, I.iii: $1.2 \%$ alginate) storage.

Figure 2: The viability of primary limbal epithelial cells stored in calcium alginate gel masses is influenced by storage conditions. Data points represent the mean $(n=3 \pm$ S.E.M.) percentage $(A)(100 \%=$ initially encapsulated live cells) or number (B) live cells extracted. * $P \leq 0.05$ indicate differences between storage conditions. Images (n $=3 ; 100 \mathrm{X}$ magnification) show colonies of cells from cell culture (C.i) and chilled (C.ii) storage. 
Figure 3: The internal pore network of calcium alginate gels. The internal surfaces of calcium alginate gel masses (A: $0.3 \%$ alginate, B: $0.6 \%$ alginate, C: $1.2 \%$ alginate) were examined using SEM. Electron micrographs (19000X magnification) represent 3 individual experiments.

Figure 4: Dimensions of calcium alginate gel masses and discs. Calcium alginate gel masses (A, C: $0.6 \%$ alginate) are approximately $12.5 \mathrm{~mm}$ in length (A) and $6 \mathrm{~mm}$ in depth (C), and $1.2 \%$ alginate gel discs $(B, C)$ are approximately $19 \mathrm{~mm}$ in length $(B)$ and $1.5 \mathrm{~mm}$ in depth (C). Images (100X magnification) represent 3 individual experiments.

Figure 5: Limbal epithelial cell viability is enhanced within a thin disc of calcium alginate gel. Data points represent the mean ( $n=3 \pm$ S.E.M.) percentage (A) $(100 \%$ $=$ initially encapsulated live cells), number (B) or mitochondrial activity $(C)$ of live cells extracted. * $P \leq 0.05$ indicate differences between storage conditions. Images $(\mathrm{n}=3$; $100 \mathrm{X}$ magnification) show colonies of cells from cell culture (D.i), ambient (D.ii) and chilled (D.iii) storage.

Figure 6: The internal pore network of HEC-modified calcium alginate gel discs. Calcium alginate (A: $1.2 \%$ alginate, C: $2.4 \%$ alginate, E: $3.6 \%$ alginate) and HECmodified calcium alginate (B: $1.2 \%$ alginate/2.4\% HEC, D: $2.4 \%$ alginate/2.4\% HEC, F: 3.6\% alginate/2.4\% HEC) gel discs were dehydrated and internal surfaces were examined using SEM. Electron micrographs (20000X magnification) represent 3 individual experiments. 
Figure 7: Corneal epithelial cell viability in HEC-modified alginate gel discs correlations with the mechanical properties of gels. Data points for cell viability represent the mean $(n=3 \pm$ S.E.M.) percentage $(100 \%=$ initially encapsulated live cells) live cells extracted. Data points for compressive moduli represent 10 individual measurements.

Figure 8: The distribution of cells in alginate and HEC-modified calcium alginate gel discs. Cells within calcium alginate (A: $1.2 \%$ alginate) or HEC-modified calcium alginate (B: $1.2 \%$ alginate/1.2\% HEC, C: $1.2 \%$ alginate/2.4\% HEC) gel discs containing corneal epithelial cells (HCE) were visualised using DAPI fluorescent nuclei stain $(n=3)$.

Supplemental Figure 1: The viability of corneal epithelial cells in HEC-modified calcium alginate gel discs. Data points represent the mean $(n=3 \pm$ S.E.M.) percentage $(A)(100 \%=$ initially encapsulated live cells $)$ or number $(B)$ of live cells extracted. Images ( $\mathrm{n}=3 ; 100 \mathrm{X}$ magnification) show colonies of cells extracted from alginate (alg) (C.i: $1.2 \%$ alginate, C.v: $2.4 \%$ alginate, C.ix: $3.6 \%$ alginate) or HECmodified alginate (C.ii: $1.2 \%$ alginate/1.2\% HEC, C.iii: 1.2\% alginate/2.4\% HEC, C.iv: 1.2\% alginate/3.6\% HEC, C.vi: $2.4 \%$ alginate/1.2\% HEC, C.vii: $2.4 \%$ alginate $/ 2.4 \%$ HEC, C.viii: $2.4 \%$ alginate $/ 3.6 \%$ HEC, C.x: $3.6 \%$ alginate/1.2\% HEC, C.xi: $3.6 \%$ alginate/2.4\% HEC, C.xii: 3.6\% alginate/3.6\% HEC) gel discs. 


\section{REFERENCES}

1. Notara M, Alatza A, Gilfillan $J$ et al. In sickness and in health: Corneal epithelial stem cell biology, pathology and therapy. Exp. Eye Res. 90 (2), 188195 (2010).

2. Colabelli Gisoldi RA, Pocobelli A, Villani CM, Amato D and Pellegrini G. Evaluation of molecular markers in corneal regeneration by means of autologous cultures of limbal cells and keratoplasty. Cornea 29 (7), 715-722 (2010).

3. Talbot M, Carrier P, Giasson CJ et al. Autologous transplantation of rabbit limbal epithelia cultured on fibrin gels for ocular surface reconstruction. Mol. Vis. 12, 65-75 (2006).

4. Deshpande P, McKean R, Blackwood KA et al. Using poly(lactide-co-glycolide) electrospun scaffolds to deliver cultured epithelial cells to the cornea Regen. Med. 5 (3), 395-401 (2010).

5. Mi S, Chen B, Wright B and Connon CJ. Ex vivo construction of an artificial ocular surface by combination of corneal limbal epithelial cells and a compressed collagen scaffold containing keratocytes. Tissue Eng Part A 16 (6), 2091-2100 (2010). 
6. Mi S, Chen B, Wright B and Connon CJ. Plastic compression of a collagen gel forms a much improved scaffold for ocular surface tissue engineering over conventional collagen gels. J Biomed Mater Res A 95 (2) 447-453 (2010).

7. Wikstrom J, Elomaa M, Syvajarvi $\mathrm{H}$ et al. Alginate-based microencapsulation of retinal pigment epithelial cell line for cell therapy. Biomaterials 29 (7) 869876 (2008).

8. Capretto L, Mazzitelli S, Luca G and Nastruzzi C. Preparation and characterization of polysaccharidic microbeads by a microfluidic technique: application to the encapsulation of Sertoli cells. Acta Biomater. 6 (2), 429-435 (2010).

9. Cook MT, Tzortzis G, Charalampopoulos D and Khutoryanskiy VV. Production and evaluation of dry alginate-chitosan microcapsules as an enteric delivery vehicle for probiotic bacteria. Biomacromolecules 12 (7) 2834-2840 (2011).

10.Krol S, del Guerra S, Grupillo M, Diaspro A, Gliozzi A and Marchetti P. Multilayer nanoencapsulation. New approach for immune protection of human pancreatic islets. Nano Lett. 6 (9), 1933-1939 (2006).

11. Cabane P, Gac P and Amat J. Allotransplant of microencapsulated parathyroid tissue in severe postsurgical hypoparathyroidism: a case report. Transplant Proc. 41 (9), 3879-3883 (2009). 
12. Kintzios S, Yiakoumetis I, Moschopoulos G, Mangana O, Nomikou K and Simonian A. Differential effect of the shape of calcium alginate matrices on the physiology of immobilized neuroblastoma N2a and Vero cells: a comparative study. Biosens. Bioelectron. 23 (4) 543-548 (2007).

13. Hunt NC, Shelton RM and Grover L. An alginate hydrogel matrix for the localised delivery of a fibroblast/keratinocyte co-culture. Biotechnol. J. 4 (5), 730-737 (2009).

14. Li RH, Altreuter $\mathrm{DH}$ and Gentile FT. Transport characterization of hydrogel matrices for cell encapsulation. Biotechnol. Bioeng. 50 (4), 365-373 (1996).

15. Hwang CM, Sant S, Masaeli M et al. Fabrication of three-dimensional porous cell-laden hydrogel for tissue engineering. Biofabrication 2 (3), 1-12 (2010).

16.Seo SJ, Choi YJ, Akaike T, Higuchi A and Cho CS. Alginate/galactosylated chitosan/heparin scaffold as a new synthetic extracellular matrix for hepatocytes. Tissue Eng. Part A 12 (1), 33-44 (2006).

17. Kuo CK and Ma PX. lonically crosslinked alginate hydrogels as scaffolds for tissue engineering: part 1. Structure, gelation rate and mechanical properties. Biomaterials 22 (6), 511-521 (2001).

18. Veriter S, Mergen J, Goebbels RM et al. In vivo selection of biocompatible alginates for islet encapsulation and subcutaneous transplantation. Tissue Eng. Part A 16 (5), 1503-1513 (2010). 
19.Bidarra SJ, Barrias CC, Barbosa MA, Soares R and Granja PL. Immobilization of human mesenchymal stem cells within RGD-grafted alginate microspheres and assessment of their angiogenic potential. Biomacromolecules 11 (8), 1956-1964 (2010).

20. Mazumder MAJ, Burke NAD, Shen F, Potter MA and Stover HDH. Core-crosslinked alginate microcapsules for cell encapsulation. Biomacromolecules 10 (6), 1365-1373 (2009).

21.Sakai S, Yamaguchi S, Takei T and Kawakami K. Oxidized alginate-crosslinked alginate/gelatin hydrogel fibers for fabricating tubular constructs with layered smooth muscle cells and endothelial cells in collagen gels. Biomacromolecules 9 (7) 2036-2041 (2008).

22. Araki-Sasaki K, Ohashi $Y$, Sasabe $T$ et al. An SV40-immortalized human corneal epithelial cell line and its characterization. IOVS 36 (3), 614-621 (1995).

23.Chen B, Mi S, Wright B and Connon CJ. Differentiation status of limbal epithelial cells cultured on intact and denuded amniotic membrane before and after air-lifting. Tissue Eng. Part A 16 (9), 2721-2729 (2010). 
24.Chhatbar M, Meena R, Prasad K and Siddhanta AK. Microwave assisted rapid method for hydrolysis of sodium alginate for $M / G$ ratio determination Carbohydr. Polym. 76 (4), 650-656 (2009).

25.Chandía NP, Matsuhiro B and Vásquez AE. Alginic acids in Lessonia trabeculata: characterization by formic acid hydrolysis and FT-IR spectroscopy Carbohydr. Polym. 46 (1), 81-87 (2001).

26.URN: 11/1056 Publication date: 18 Jul 2011 Available from URL: http://www.bis.gov.uk/publications/whats-new

27. Slaughter BV, Khurshid SS, Fisher OZ, Khademhosseini A and Peppas NA. Hydrogels in regenerative medicine. Adv. Mater. 21 (32-33), 3307-3329 (2009).

28. Ko HF, Sfeir C and Kumta PN. Novel synthesis strategies for natural polymer and composite biomaterials as potential scaffolds for tissue engineering. Philos. Transact. A Math Phys. Eng. Sci. 368 (1917), 1981-1997 (2010).

29. Davis IS, Shachar-Hill B, Curry MR, Kim KS, Pedley TJ and Hill AE. Osmosis in semi-permeable pores: an examination of the basic flow equations based on an experimental and molecular dynamics study Proc. R. Soc. A 463 (2079), 881-896 (2007).

30. Orive G, Tam SK, Pedraz JL and Halle JP. Biocompatibility of alginate poly-Llysine microcapsules for cell therapy. Biomaterials 27 (20) 3691-3700 (2006). 
31. Utheim TP, Raeder S, Utheim OA et al. A novel method for preserving cultured limbal epithelial cells. Br. J. Ophthalmol. 91 (6), 797-800 (2007).

32. Faustini M, Bucco M, Galeati $G$ et al. Boar sperm encapsulation reduces in vitro polyspermy. Reprod. Domest. Anim. 45 (2), 359-362 (2010).

33. Tamponnet C, Boisseau S, Lirsac PN et al. Storage and growth of neuroblastoma cells immobilized in calcium-alginate beads. Appl. Microbiol. Biotechnol. 33 (4), $442-447$ (1990).

34. Sakurai $T$, Kimura $M$ and Sato $M$. Temporary developmental arrest after storage of fertilized mouse oocytes at 4 degrees C: effects on embryonic development, maternal mRNA processing and cell cycle. Mol. Hum. Reprod. 11 (5), 325-333 (2005).

35. Dontchos, B. N.; Coyle, C. H.; Izzo, N. J.; et al. Optimizing $\mathrm{CO}_{2}$ normalizes pH and enhances chondrocyte viability during cold storage. J. Orthop. Res. 26 (5), 643-650 (2008).

36. Horbinski C, Mojesky C and Kyprianou N. Live free or die: tales of homeless (cells) in cancer. Am. J. Pathol. 177 (3), 1044-1052 (2010). 